\title{
LECTURE
}

\section{Early Detection of Melanoma Progression by Quantitative Real-time RT-PCR Analysis for Multiple Melanoma Markers}

\author{
Peter Arenberger, ${ }^{1}$ Monika Arenbergerova, ${ }^{1}$ Olga Vohradnikova, ${ }^{1}$ \\ and Jaromir Kremen ${ }^{2}$ \\ ${ }^{1}$ Department of Dermatovenereology, Charles University $3^{\text {rd }}$ Medical Faculty, \\ Srobarova 50, CZ 10034 Prague 10, Czech Republic \\ ${ }^{2}$ Department of Chemistry and Biochemistry, Charles University $3^{\text {rd }}$ Medical Faculty, \\ Srobarova 50, CZ 10034 Prague 10, Czech Republic
}

(Received for publication on June 18, 2007)

(Revised for publication on September 28, 2007)

(Accepted for publication on November 15, 2007)

\begin{abstract}
Standard screening of melanoma patients is a useful tool for predicting outcome of patients, however, an instant methodology for exact detection of subclinical disease or monitoring treatment response is under investigation.

Detection of circulating melanoma cells is, therefore, a possible novel promising staging method. However, inconsistent data on method sensitivity and on the predicted patient outcome has been shown repeatedly.

Recently, a multimarker real-time RT-PCR methodology for quantification of five melanoma markers Melan-A, gp 100, MAGE-3, MIA and tyrosinase was described by our group. In the current prospective trial, blood specimens of 65 patients with AJCC stage IIB-III cutaneous melanoma after surgery were periodically examined. In the above group, $27 \%$ of subjects relapsed during the study. Prior to the disease progression we could observe a statistically significant tumor marker elevation in previous 0 to 9 months in all patients with clinical relapse. MAGE-3 became the most sensitive progression marker. During progression, three concordant positive markers were seen in $39 \%$ of patients, followed by two concordant positive markers in $28 \%$ and 1 marker in $33 \%$.

This study supports the use of a multimarker real-time RT-PCR as a disease progression predictor. The dynamic assessment of serially obtained blood specimens represents a useful method for early metastasis detection and treatment response of melanoma patients. (Keio J Med 57 (1) : 57-64, March 2008)
\end{abstract}

Key words: malignant melanoma, melanoma markers, circulating melanoma cells

\section{Introduction}

Melanoma belongs to the most malignant tumors of the skin and mucous membranes due to its aggressive biological behavior and tendency to generate early metastases. The development of metastasis in lymphatic system is described in $70 \%$ of metastatic melanoma; the haematogenous metastazing affects usually liver, lung, brain and bones.

The sensitivity of current diagnostic methods increases rapidly, however, nowadays imaging methods are able to inform about the presence of lymph node or visceral metastasis usually in an advanced stage only. Therefore, new, improved non-invasive methods, which would enable to detect tumor cells in the blood stream of the patient, are urgently demanded. The detection of melanoma cells in the peripheral blood could serve as an important method for predicting clinical outcome of the patient.

Usually, only limited amount of tumor cells may be

Presented at the 1513rd Meeting of the Keio Medical Society in Tokyo, April 3, 2007

Corresponding Author: Prof. Peter Arenberger, MD, PhD, DSc, MBA, Chairman at the Dept. of Dermatovenereology, Charles University Third Medical Faculty, Srobarova 50, CZ 10034 Prague 10, Czech Republic, E-mail: pa@avemedica.cz 
present in blood. Therefore, molecular biology methods using reverse transcription (RT) followed by polymerase chain reaction, characterized by high sensitivity and specificity for detection of mRNAs encoding protein have been used. These are specific for certain tumor cell subtypes. Real-time RT-PCR methodology used in the present work enables even more accurate quantification of mRNA genes.

The detection of circulating melanoma cell has been proposed as a sensitive method for selecting patients who are in a high risk to relapse. ${ }^{1,2}$ However, after the original description of molecular monitoring of circulating melanoma cells by reverse transcriptase-PCR (RT-PCR) had been published, ${ }^{3}$ inconsistent data on sensitivity and clinical relevance of this method have been reported ${ }^{4-15}$. Two possible reasons for the conflicting results may exist: (a) a single marker detection, (b) conventional or semiquantitative RT-PCR assay. Explaining the first point (a), heterogeneity of the expression of melanoma antigens poses one of the major problems in detection of circulating melanoma cells. ${ }^{1}$ Single marker detection has a limited value as a prognostic marker and the multiple marker assay including other tumor associated antigens is suggested to increase the sensitivity and specificity of this method. ${ }^{16}$ Moreover, the majority of these studies investigated tyrosinase as a unique marker, however its usefulness as a melanoma marker is highly debated. ${ }^{17,18}$ Objections to the second argument (b) are as follows. There are limitations of conventional or semiquantitative RT-PCR as a prognostic marker. In contrast, a quantitative real time PCR offers a quick and accurate approach. It measures housekeeping gene expression and expression of melanoma associated RNA and thus allows rapid and reproducible quantitative analysis of melanoma markers. ${ }^{19,20}$

Only a limited number of tumor associated markers expressed by melanoma cells specifically have been identified. In this study, we investigated five presumable predictive markers for primary and metastatic melanoma: melanoma antigen recognized by $\mathrm{T}$ cells (Melan-A/ MART-1), melanosomal matrix protein (gp 100), melanoma antigen-A3 family (MAGE-3), melanoma inhibitory protein (MIA) and key enzyme in biosynthesis of melanin (tyrosinase). Additional serum tumor markers have been shown to be relevant for prognosis of patients with different types of cancer. ${ }^{21-24}$

In the prospective study 65 melanoma patients stage IIB -III were enrolled. Peripheral blood samples were collected every three months for following 18 months and circulating melanoma cells were examined and compared with clinical staging results. Eighteen patients relapsed during the trial and showed different types of melanoma progression. All these patients experienced concomitant statistically significant tumor marker elevation in the period up-to 9 months before the disease pro- gression. Our experience showed that MAGE-3 was the most sensitive progression marker. In patients with progression we found three concordant positive markers in $39 \%$ of cases, two concordant positive markers in $28 \%$ and finally one marker in $33 \%$.

We established a quantitative multimarker real time RT-PCR assay, giving exact information about the level of different markers in the blood. This method provides information on the frequency of melanoma-associated gene transcripts and helps to monitor their dynamics in the blood during a certain time period. The final aim of the present study is the routine usage of this method for rapid screening of early metastasis and treatment response in high risk melanoma patients.

\section{Methods}

\section{Patient selection}

In total 65 patients participated in the study. The group consisted of 39 men and 26 women at the age of 20-75 years. The average age of the patients was 55 years. Only patients with histologically verified resected melanoma in stage IIB-IIIC were enrolled. The stage of the disease was determined according to the American Joint Committee on Cancer guidelines. ${ }^{25-27}$ We selected patients after surgical resection of melanoma who were treated during the whole study period with immunotherapy with interferon alpha 2 a $(3 \times 6$ MIU subcutaneously every week). Patients were enrolled into the study after 4 weeks of interferon alpha run-in treatment and were clinically examined at the enrollment day and then every three months during a period of 18 months. At the same time the trial blood collection and complete staging were performed.

\section{RNA isolation from blood samples}

Seven $\mathrm{ml}$ of peripheral blood was collected into EDTA coated tube and the blood sample was processed within following 2 hours. Total cellular RNA was extracted from non-erythrocytic cellular population obtained by centrifugation $(30 \mathrm{~min}, 1200 \mathrm{x} \mathrm{g})$ using Histopaque Sigma 1119 and 1077 (2:1) gradient. For RNA isolation High Pure RNA Isolation Kit (Roche Diagnostics GmbH, Germany) or MagNA Pure Compact (Roche Diagnostics $\mathrm{GmbH}$, Germany) device assisted methodology together with MagNA Pure Compact RNA Isolation Kit (Roche Diagnostics GmbH, Germany) were used. RNA quality was determined electrophoretically in $1.5 \%$ agars gel with ethidium bromide and quantity was checked spectrophotometrically.

\section{Melanoma cell lines}

RNA from the cell line SK-MEL 28 was kindly provided by M. Vejražka, MD., PhD., Institute of Medical Biochemistry, Prague. This cell line is expressing the panel 
Table 1 Primer and Light Cycler probes sequences

\begin{tabular}{|c|c|c|c|c|}
\hline & hu TYR, mRNA & & NM_000372 & Tm \\
\hline HTYR-F & TCTTCTCCTCTTggCAgATTgT & $\mathrm{S}$ & $1305-1326$ & $56.2^{\circ} \mathrm{C}$ \\
\hline \multirow[t]{2}{*}{ HTYR-R } & CAgTAAgTggACTAgCAAATCCTTC & A & $1559-1535$ & $56.3^{\circ} \mathrm{C}$ \\
\hline & FRET probe hu TYR, mRNA & & & \\
\hline HTYR-FL & CCAAggCTCCССТCTTCAgCTg X & $\mathrm{S}$ & $1430-1451$ & $65.2^{\circ} \mathrm{C}$ \\
\hline \multirow[t]{2}{*}{ HTYR-LC } & TgTAgAATTTTgCCTgAgTTTgACCCAAT p & $\mathrm{S}$ & $1453-1481$ & $64.2^{\circ} \mathrm{C}$ \\
\hline & Primer hu Melan A, mRNA & & NM_005511 & Tm \\
\hline Melan-se & TggATAAAAgTCTTCATgTTggC & $\mathrm{S}$ & $226-248$ & $55.9^{\circ} \mathrm{C}$ \\
\hline \multirow[t]{2}{*}{ Melan-as } & gTggAgCATTgggAACCAC & A & $357-339$ & $57.6^{\circ} \mathrm{C}$ \\
\hline & FRET probe hu Melan A & & & \\
\hline Melan-FL & gCTgTCCCgATgATCAAACCCTTC X & A & $305-282$ & $64.3^{\circ} \mathrm{C}$ \\
\hline \multirow[t]{2}{*}{ Melan-LC } & TgTgggCATCTTCTTgTTAAggCACA p & A & $280-255$ & $65.2^{\circ} \mathrm{C}$ \\
\hline & hu Primer MAGE3, mRNA & & NM_175742 & Tm \\
\hline MAGE3-S & gAgAAgATCTgCCAgTgggTCT & $\mathrm{S}$ & $135-156$ & $58.3^{\circ} \mathrm{C}$ \\
\hline \multirow[t]{2}{*}{ MAGE3-A } & gCCTCCTgCTCCTCAgTAgC & $\mathrm{A}$ & $322-303$ & $58.3^{\circ} \mathrm{C}$ \\
\hline & FRET probe hu MAGE3 & & & \\
\hline MAGE3-FL & gAggCATgATgACTCTggTCAgggC X & $\mathrm{A}$ & $216-192$ & $66.3^{\circ} \mathrm{C}$ \\
\hline \multirow[t]{2}{*}{ MAGE3-LC } & ACAggCgggAgTgTgggCA p & A & $190-172$ & $66.6^{\circ} \mathrm{C}$ \\
\hline & Primer hu gp100 mRNA & & NM_006928 & $\bar{T} \mathbf{T m}$ \\
\hline gp100 F & AAggTCCAgATgCCAgCTCAATCA & $\mathrm{S}$ & $1341-1364$ & $63.6^{\circ} \mathrm{C}$ \\
\hline \multirow[t]{2}{*}{ gp100 R } & AggATCTCggCACTTTCAATACCC & $\mathrm{A}$ & $1527-1504$ & $61.7^{\circ} \mathrm{C}$ \\
\hline & FRET probe hu gp100 mRNA & & & \\
\hline gp100 FL & AgTCCCCCTggATTgTgTTCTgTATCgA X & $\mathrm{S}$ & $1441-1468$ & $66.5^{\circ} \mathrm{C}$ \\
\hline gp100 LC & TggTTCCTTTTCCgTCACCCTggAC p & $\mathrm{S}$ & $1471-1495$ & $67.9^{\circ} \mathrm{C}$ \\
\hline
\end{tabular}

of melanoma markers tested in the present work. RNA obtained from the cell suspension diluted to concentration of $10^{5}-10^{1}$ was used for sensitivity testing of this method.

\section{Negative control}

Blood samples from 23 healthy donors served as a negative control.

\section{Melanoma markers examined}

Expression of the following mRNA markers was examined using a quantitative real-time RT-PCR: MIA (melanoma inhibitory antigen), Melan-A/ MART-1 (melanoma antigen recognized by $\mathrm{T}$ cells), MAGE-3 (melanoma antigen gene-3), gp100 (melanosomal matrix glycoprotein) and hTYR (tyrosinase).

\section{Quantitative real-time RT-PCR}

Amplification of target sequences of examined markers was performed by 2 step quantitative RT-PCR with primers and probes listed in Table 1. Primers and LightCyler probes were designed and synthesized at TIB-MolBiol (Berlin, Germany). The first probe was labeled by fluorescein, as donor fluorophore, at the $3^{\prime}$-end whereas the second one by R-640, as acceptor fluorophore, at the $5^{\prime}$ -end and the 3'-end was blocked by phosphate.

In the first step, cDNA was synthesized from $2.0 \mu \mathrm{g}$ of total cellular RNA via First Strand cDNA Transcriptor Synthesis Kit (Roche Diagnostics GmbH, Germany) according to producer recommended conditions, using random hexanucleotides primers. The use of random hexamer primers provides priming throughout the length of RNA for uniform representation of all RNA sequences and, in addition, allows reverse transcription of RNAs that do not carry a poly(A) tail.

In the second step, $2.5 \mu \mathrm{l}$ of marker cDNA was amplified in $10 \mu 1$ of total volume of LightCycler FastStart DNA Master ${ }^{\text {PLUS }}$ Hybridization Probes Kit (Roche Diagnostics $\mathrm{GmbH}$, Germany) supplemented by above listed primers, LightCycler probes, and LC-Uracil-N-glycosylase (Roche Diagnostics GmbH, Germany) for the selective destruction of carryover products.

For kinetic real-time PCR LightCycler Instrument (Roche Diagnostics GmbH, Germany) under following conditions was used: $37^{\circ} \mathrm{C} / 10$ min incubation with $\mathrm{LC}$ uracil-N-glycosylase; $95^{\circ} \mathrm{C} / 10 \mathrm{~min}$ inactivation of uracil$\mathrm{N}$-glycosylase and concomitant activation of LC Fast TaqPolymerase; amplification 55 cycles: $95^{\circ} \mathrm{C} / 10 \mathrm{~s}, 55^{\circ}$ $\mathrm{C} / 10 \mathrm{~s}$ (fluorescence measurement), $72^{\circ} \mathrm{C} / 13 \mathrm{~s}$. The product check was performed by Tm determination. Ex- 
pression of each marker was compared with the PBGD (porphobilinogen deaminase) housekeeping gene expression using LightCycler-h-PBGD Housekeeping Gene Set (Roche Diagnostics GmbH, Germany).

\section{Data analysis}

Numbers of amplified marker RNA copies/ml were related to number of housekeeping gene copies (number of marker copies/ml: number of PBGD copies $/ \mathrm{ml}$ ). The statistical analysis was performed using SPSS software (release 10.0) and the Student's $t$ test.

\section{Results}

\section{Study protocol}

All patients had given informed consent before entering the study. In total 65 patients with resected cutaneous malignant melanoma were enrolled into the study. Patients were stratified according to the recent American Joint Committee on Cancer classification. ${ }^{25-27}$ We have enrolled $33.9 \%$ patients in stage IIA, $24.6 \%$ patients in stage IIB, $12.3 \%$ patients in stage IIC, $15.4 \%$ patients in stage IIIA, $9.2 \%$ patients in stage IIIB and $4.6 \%$ patients in stage IIIC. Blood samples for detection of circulating cells were collected every three months during a period of 18 months. At the same time standard staging procedures were performed: lymph node ultrasound, abdominal ultrasound and chest $\mathrm{x}$-ray. Other imaging methods were performed individually according to the specific need of the patient.

\section{Expression of Melan-A, gp 100, MAGE-3, MIA and tyrosinase mRNA in blood samples of tumor progres- sion patients}

Within a follow-up of 18 months, 18 out of 65 patients developed tumor progression. We could observe elevation of 1 to 3 tumor markers in all patients with progression. Subjects were members of IIA-IIIB initial stage groups. In particular 5 patients were in stage IIA, 3 patients in stage IIB, 4 patients in stage IIC, following 4 in stage IIIA and 2 in stage IIIB. Results of tumor marker levels were compared in each patient with cutoff marker levels measured in the healthy volunteer group.

Tumor marker level (marker/PBGD) for MIA was $0.832 \pm 0.073$, for Melan-A $0.012 \pm 0.002$, for MAGE-3 $2.75 \pm 0.302$ and for gp $1000.057 \pm 0.006$. Values represent mean \pm SD. Tumor marker mean levels in patients with progression are shown in the same format and they are as follows: MIA $4.272 \pm 2.183$ (statistically significant difference compared with cutoff value, $\mathrm{p}<0.01$ ), for Melan-A $0.026 \pm 0.016$ (statistically non-significant difference compared with cutoff value, $p>0.05$ ), for MAGE-3 332.927 \pm 196.239 (statistically significant difference compared with cutoff value, $\mathrm{p}<0.01$ ) and for gp100 $0.953 \pm 0.827$ (statistically significant difference compared with cutoff value, $\mathrm{p}<0.05$ ).

Table 2 gives an overview on marker levels in all 18 patients in progression displayed as cutoff value multiples. In MIA the mean progression/cutoff ratio was 5.08, in MAGE-3 153.07 and in gp100 16.72. Tyrosinase was positive in 1 patient with progression and none of the patients developed significant increase of Melan-A marker level compared to cutoff ( $\mathrm{p}>0.05)$.

Elevation of different markers is significantly associated with the disease progression.

\section{Expression of examined markers in tumor progres- sion patients}

Samples were most often positive for MAGE-3 (17 out of 18 samples, $94.4 \%$ ), followed by gp100 (10 out of 18 patients, $55.6 \%$ ), MIA ( 9 out of $18,50 \%$ ) and tyrosinase ( 1 out of $18,5.6 \%$ ). Melan-A showed no statistically significant positive values (samples above cutoff) in patients suffering from melanoma progression (Fig. 1). In patients with progression the most frequent number of concordant positive markers was three in $39 \%$ of cases followed by 1 marker (33\%) and finally by 2 markers in $28 \%$.

\section{Correlation with clinical parameters}

Tumor marker elevation was observed in 21 out of 65 patients. Eighteen patients (86\%) suffered from disease progression during the 18 months follow-up as described in Table 1 in detail. All these patients with progression from our group showed elevation of single marker or concordant elevation of 2 or 3 markers. Three more patients $(14 \%)$ displayed statistically significant elevated markers above the cutoff level without clinical signs of progression up-to now.

\section{Elevation of the tumor markers preceded clinical pro- gression up-to 9 months}

We could observe the elevation of the tumor markers in most cases much earlier before the first clinical signs of progression. According to the protocol, blood samples were examined every 3 months for the detection of circulating cells and at the same time imaging staging methods were carried out. We could observe an elevation of the markers 9 months in advance in $28 \%$ of the patients, 6 months in advance in $38 \%$ of the patients, 3 months in advance in $17 \%$ of the patients and only $17 \%$ of patients displayed elevation of the markers at the same time as clinical progression occurred.

\section{Discussion}

The AJCC classification ${ }^{25-27}$ plays an important role in the determination of the melanoma patient prognosis and his life expectancy. Lower AJCC index signifies a better prognosis for the patient, whereas higher index means a worsened prognosis. Although the sensitivity of diag- 


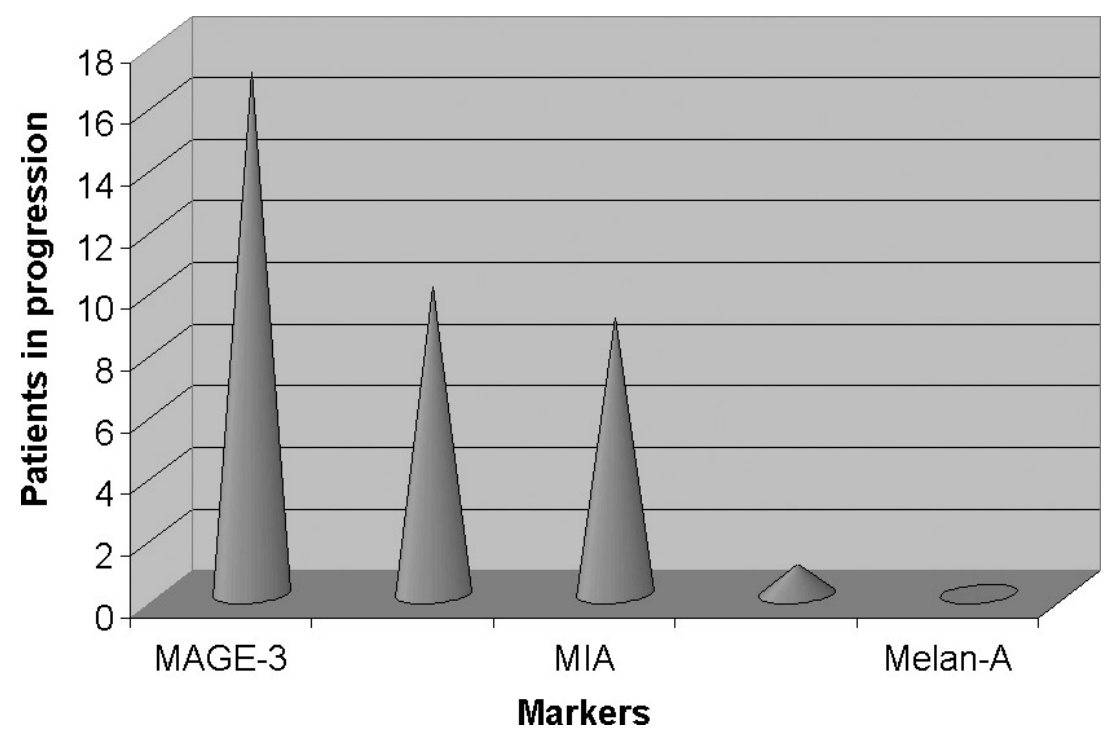

Fig. 1 Expression of examined tumor markers in patients with melanoma progression. MAGE-3 was the most frequent positive marker (17x) in this group, followed by gp100 (10x), MIA (9x) and tyrosinase (1x). Melan-A did not show any significant elevation compared with cutoff.

nostic methods is increasing rapidly, contemporary imaging methods are able to inform us about the disease only in its advanced stage. Therefore, we are permanently searching for a method, which would be able to detect tumor cells in the blood stream of the patient. Detection of circulating tumor cells is an attractive assessment approach because tumor cells in peripheral blood are essential for the formation of metastatic lesions and because this analysis can depict real-time tumor status.

Evaluation of studies with serum markers such as lactate dehydrogenase (LDH), S100 protein or neuron-specific enolase (NSE) could show that these serologic tumor markers are not sensitive enough for an early detection of progression or therapy efficacy control. ${ }^{28}$

In this study, we could demonstrate the uselfulness of multimarker real-time RT-PCR as a sensitive and specific quantitative assay to detect circulating melanoma cells in the blood. The quantitative real-time RT-PCR enables to quickly analyze large number of samples and reduces the risk of carryover contamination. Moreover, this method offers accurate and reproducible mRNA gene quantification.

Every three months we detected melanoma markers from peripheral blood using this methodology. During 18 months of the study run, melanoma markers significantly increased above the cutoff line in 21 patients. In 18 out of 21 patients $(86 \%)$ the clinical progression of the disease occured also during the study run. Three patients of the above mentioned group (16\%) showed elevated marker levels but this increase was not linked to the disease progression. The explanation for these three patients could be a false positive marker level result or a prolonged period between the marker level elevation and a clinical metastasis onset. All three patients are still within the window of less than 9 months from the marker level increase, which means that according to our knowledge we can, unfortunately, nearly expect a clinical progression of the disease. These patients are under detailed frequent follow-up supervision. In the meantime, prostata cancer was developed by one of these patients.

In general, the elevation of the tumor marker levels occured in the majority of cases significantly earlier compared with the clinical progression. We could demonstrate that the earliest marker elevation happened 9 months before the disease progression in $28 \%$ of patients, 6 months before in $38 \%, 3$ months before in $17 \%$ and at the same time matching with the progression diagnosed by clinical and/or imaging method in another $17 \%$. Thus, elevation of tumor markers can be considered as an early method for haematogenous spread and development of metastasis.

Melanoma tumors are heterogenous in tumor-associated marker expression. Heterogeneity of melanoma marker expression in blood makes multimarker RT-PCR advantageous compared to single-marker detection of circulating melanoma cells.

The real-time RT-PCR assay has high throughput capacity that can analyze large number of samples without PCR product carryover contamination. It is a very accurate and reproducible method. This assay system can detect melanoma cells among millions of peripheral blood leucocytes without requiring cell-separation methods 
Table 2 Elevation of melanoma markers in 18 out of 65 patients with clinical progression. Numbers listed in the table express elevation of markers as multiplicates of cutoff value.

\begin{tabular}{|c|c|c|c|c|c|c|c|}
\hline $\begin{array}{l}\text { Patient } \\
\text { No. }\end{array}$ & \begin{tabular}{|l|} 
Initial \\
stage
\end{tabular} & $\begin{array}{l}\text { MIA } \\
\text { progression / } \\
\text { cutoff }\end{array}$ & $\begin{array}{l}\text { Melan-A } \\
\text { progression / } \\
\text { cutoff }\end{array}$ & $\begin{array}{l}\text { MAGE-3 } \\
\text { progression / } \\
\text { cutoff }\end{array}$ & \begin{tabular}{|l|} 
gp 100 \\
progression / \\
cutoff
\end{tabular} & $\begin{array}{l}\text { tyrosinase } \\
\text { progression / } \\
\text { cutoff }\end{array}$ & \begin{tabular}{|l}
$\begin{array}{l}\text { Type of } \\
\text { progression } \\
\text { (metastases) }\end{array}$ \\
\end{tabular} \\
\hline 1 & IIB & 13.3 & normal & 1019.4 & normal & normal & satellite \\
\hline 2 & IIA & 6.4 & normal & 40580 & normal & normal & \begin{tabular}{|l|} 
regional \\
lymph node
\end{tabular} \\
\hline 6 & IIA & normal & normal & 257.5 & normal & normal & satellite \\
\hline 7 & IIC & 3.3 & normal & 5857 & normal & normal & \begin{tabular}{|l|} 
regional \\
lymph node
\end{tabular} \\
\hline 8 & IIIA & 109.6 & normal & 23241 & normal & normal & \begin{tabular}{|l} 
regional \\
lymph node
\end{tabular} \\
\hline 10 & IIC & 2.3 & normal & 3.3 & 88.0 & normal & liver \\
\hline 14 & IIIB & 2.2 & normal & 6.1 & normal & normal & kidney,lung \\
\hline 17 & IIB & 31.9 & normal & 623 & 93.1 & normal & in-transit \\
\hline 20 & IIC & normal & normal & 19516 & normal & normal & skin, brain \\
\hline 21 & IIC & 30.5 & normal & 438 & normal & normal & brain \\
\hline 24 & IIA & normal & normal & 113179 & 398.7 & normal & \begin{tabular}{|l|} 
regional \\
lymph node
\end{tabular} \\
\hline 25 & IIIA & 7.7 & normal & 5664 & 5.2 & normal & \begin{tabular}{|l|} 
regional \\
lymph node
\end{tabular} \\
\hline 28 & IIB & 8.0 & normal & 105.6 & normal & normal & liver \\
\hline 35 & IIA & 1.5 & normal & 36.4 & normal & normal & brain \\
\hline 44 & IIIB & 3.7 & normal & 25833 & normal & normal & $\begin{array}{l}\text { regional } \\
\text { lymph node }\end{array}$ \\
\hline 58 & IIIA & 2.5 & normal & normal & 16.2 & positive & peritoneum \\
\hline 60 & IIA & 11.9 & normal & 11673 & normal & normal & eye, satellite \\
\hline 62 & IIIA & normal & normal & 318 & normal & normal & $\begin{array}{l}\text { regional } \\
\text { lymph node, } \\
\text { satellite }\end{array}$ \\
\hline
\end{tabular}

such as magnetic beads, separation medium or other approaches. $^{29}$

In our study we concentrated on 5 melanoma markers: Melan-A/MART-1, gp 100, MAGE-3, MIA a tyrosinase. MAGE-3 was identified as the most sensitive progression marker (elevation in 17 out of 18 patients), followed by gp 100 (10 out of 18), MIA (9 out of 18) and tyrosinase with 1 elevation. In Melan-A no statistically significant increase compared with cutoff for all studied patients experiencing progression was shown. In the past, tyrosinase was used as a usual and single marker for detection of circulating cells. Its role as a melanoma marker is highly debated and explanations vary in different papers. In published studies using tyrosinase as a sole marker, the range of patients found to be positive for circulating melanoma cells varied from $6 \%$ to $59 \% .^{17,30-33}$ We could speculate about the technical mistake in the previously published papers, i.e. high percentage of false positive results because of e.g. contamination reasons or tyrosinase down-regulation in advanced stages, which is characterized by reduction of tumor cell differentiation and low content of melanin in the tumor cells. ${ }^{34}$ In contrast, in our study we found most frequently three concomitantly positive markers and, therefore, we can dem- onstrate the multimarker real-time RT-PCR as useful and sensitive one.

As an interesting fact we can note that the tumor marker elevation in the peripheral blood was connected not only to the haematogenous spread, but also to the development of lymphogenic metastasis. This finding can explain the fact that the presence of lymph node metastasis significantly reduces an overall survival.

In our study, tumor markers were examined every three months. This interval is important to get the marker elevation data as soon as possible before the onset of progression. The question is, whether 3 month interval may be considered as optimal, or too short or too long. Important limitation is as well the financial aspect of the examination and technical difficulties concerning the patient. The RNA isolation has to be carried out two hours after the blood collection. This means that the patient has to travel into the study centre. On the other hand, the optimal examination frequency between two blood collections from the medical point of view should be very short.

Repeated monitoring of tumor marker levels is important also for another reason. In some of the blood collections in previously positive patients, tumor cells do not 
appear. This is what we could observe also in two patients who experienced clinical progression. In both of them we found 4 positive and 1 negative from 5 blood samples (in the first patient: No.1 pos., No. 2 pos., No. 3 neg., No.4 pos., No.5 pos. and in the second patient No. 1 pos., No. 2 neg., No. 3 pos., No. 4 pos., No. 5 pos.). We consider the negative value as false negative. There are several reasons for this observation: non-homogenous distribution of tumor cells in the blood stream, direct or indirect adjuvant immunotherapy influence on tumor marker level, variable time dependent biological behavior of the tumor tissue, and many others. ${ }^{35,36}$ Our experience showed that 3-month intervals are just a well-balanced option considering the financial aspect on one hand and data quality on the other hand.

It seems that circulating melanoma cell detection should be a useful tool to quality enhancement of the diagnostic and follow-up process in malignant melanoma patients which could be confirmed not only by our results but also by the recent meta-analysis study with 5433 patients and 53 studies. ${ }^{37}$ However, this meta-analysis points out the heterogeneity of the studies cited and, therefore, it is of great importance to use a standard methodology in the future.

In conclusion, the multimarker quantitative real-time RT-PCR used in the present study is a sensitive method for the detection of circulating melanoma cells. It could serve as a useful tool for early detection of metastatic process. This laboratory methodology can possibly open new insights into the principles of tumor microenvironment and metastasizing.

We presume that results of our study may lead to the routine usage of this method for rapid screening of risk patients, and a better insights in the monitoring of the effects of adjuvant therapy in the near future. Evaluation of larger patient cohorts with longer follow-up should be of particular advantages to confirm the ability of realtime RT-PCR assay to predict the prognosis of melanoma patients.

\section{Acknowledgements}

This work was supported by the IGA 1A/8243-3 Czech Ministry of Health grant.

\section{References}

1. Hoon DS, Wang Y, Dale PS, Conrad AJ, Schmid P, Garrison D: Detection of occult melanoma cells in blood with a multiplemarker polymerase chain reaction assay. J Clin Oncol 1995; 13: 21092116

2. Mocellin S, Del Fiore P, Guarnieri L, Scalerta R, Foletto M, Chiarion $\mathrm{V}$ et al: Molecular detection of circulating tumor cells is an independent prognostic factor in patients with high-risk cutaneous melanoma. Int J Cancer 2004;111:741-5

3. Smith B, Selby P, Southgate J, Pittman K, Bradley C, Blair GE: Detection of melanoma cells in peripheral blood by means of reverse transcriptase and polymerase chain reaction. Lancet 1991; 338: $1227-1229$

4. Berking C, Schlüpen EM, Schrader A, Atzpodien J, Volkenandt M: Tumor markers in peripheral blood of patients with malignant melanoma.: Multimarker RT-PCR versus a luminoimmunometric assay for S-100. Arch Dermatol Res 1999; 291: 479-484

5. Blaheta HJ, Paul T, Sotlar K, Maczey E, Schittek B, Paul A, Moehrle M, Breuninger H, Bueltmann B, Rassner G, Garbe C: Detection of melanoma cells in sentinel lymph nodes, bone marrow and peripheral blood by a reverse transcription-polymerase chain reaction assay in patients with primary cutaneous melanoma: association with Breslow's tumour thickness. Br J Dermatol 2001; 145:195-202

6. Curry BJ, Myers K, Hersey P: MART-1 is expressed less frequently on circulating melanoma cells in patients who develop distant compared with locoregional metastases. J Clin Oncol 1999; 17: $2562-2571$

7. Foss AJ, Guille MJ, Occleston NL, Hykin PG, Hungerford JL, Lightman S: The detection of melanoma cells in peripheral blood by reverse transcription polymerase chain reaction. Br J Cancer 1995; 72: $155-159$

8. Ghossein RA, Coit D, Brennan M, Zhang ZF, Wang Y, Bhattacharya S, Houghton A, Rosai, J: Prognostic significance of peripheral blood and bone marrow tyrosinase messenger RNA in malignant melanoma. Clin Cancer Res 1998; 4: 419-428

9. Hanekom GS, Stubbings HM, Johnson CA, Kidson SH: The detection of circulating melanoma cells correlates with tumour thickness and ulceration but is not predictive of metastasis for patients with primary melanoma. Melanoma Res 1999; 9: 465-473

10. Le Bricon T, Stoitchkov K, Letellier S, Guibal F, Spy J,Garnier JP, Bousquet B: Simultaneous analysis of tyrosinase mRNA and markers of tyrosinase activity in the blood of patients withmetastatic melanoma. Clin Chim Acta 1999; 282: 101-113

11. Mellado B, Del Carmen Vela, M, Colomer D, Gutierrez L, Castel T, Quinto L, Fontanillas M, Reguart N, Domingo-Domenech JM, Montagut C, Estape J, Gascon P: Tyrosinase mRNA in blood of patients with melanoma treated with adjuvant interferon. J Clin Oncol 2002; 20: 4032-4039

12. Palmieri G, Strazzullo M, Ascierto PA, Satriano SMR, Daponte A, Castello G: Polymerase chain reaction-based detection of circulating melanoma cells as an effective marker of tumor progression. Melanoma Cooperative Group. J Clin Oncol 1999; 17: 304-311

13. Proebstle TM, Jiang W, Högel J, Keilholz U, Weber L, Voit C: Correlation of positive RT-PCR for tyrosinase in peripheral blood of malignant melanoma patients with clinical stage, survival and other risk factors. Br J Cancer 2000; 82: 118-123

14. Schittek B, Bodingbauer Y, Ellwanger U, Blaheta HJ, Garbe C: Amplification of MelanA messenger RNA in addition to tyrosinase increases sensitivity of melanoma cell detection in peripheral blood and is associated with the clinical stage and prognosis of malignant melanoma. Br J Dermatol 1999; 141: 30-36

15. Tsukamoto K, Ueda M, Hirata S, Osada A, Kitamura R, Takahashi T, Ichihashi M, Shimada S: gp100 mRNA is more sensitive than tyrosinase mRNA for RT-PCR amplification to detect circulating melanoma cells in peripheral blood of melanoma patients. J Der- 
matol Sci 2000; 23: 126-131

16. Hoon DSB, Bostick P, Kuo C, Okamoto T, Wang H-J, Elashoff R, Morton DL: Molecular markers in blood as surrogate prognostic indicators of melanoma recurrence. Cancer Res 2000; 60: 22532257

17. Glaser R, Rass K, Seiter S, Hauschild A, Christophers E, Tilgen W: Detection of circulating melanoma cells by specific amplification of tyrosinase complementary DNA is not a reliable tumor marker in melanoma patients: a clinical two-center study. J Clin Oncol 1997; 15:2818-2825

18. Jung FA, Buzaid AC, Ross MI, Woods KV, Lee JJ, Albitar M et al: Evaluation of tyrosinase mRNA as a tumor marker in the blood of melanoma patients. J Clin Oncol 1997;15:2826-2831

19. Keilholz U, Goldin-Lang P, Bechrakis NE, Max N, Letsch A, Schmittel A et al: Quantitative detection of circulating tumor cells in cutaneous and ocular melanoma and quality assessment by realtime reverse transcriptase-polymerase chain reaction. Clin Cancer Res 2004;10:1605-1612

20. Schuster R, Max N, Mann B, Heufelder K, Thilo F, Grone J et al: Quantitative real-time RT-PCR for detection of disseminated tumor cells in peripheral blood of patients with colorectal cancer using different mRNA markers. Int J Cancer 2004;108:219-227

21. Dasi F, Martinez-Rodes P, March JA, Santamaria J, Martinez-Javaloyas JM, Gil M, Alino SF: Real-time quantification of human telomerase reverse transcriptase mRNA in the plasma of patients with prostate cancer. Ann N Y Acad Sci 2006;1075:204-210

22. Leelawat K, Leelawat S, Ratanachu-Ek T, Trubwongchareon S, Wannaprasert J, Tripongkaruna S, Chantawibul S, Tepaksorn P: Circulating hTERT mRNA as a tumor marker in cholangiocarcinoma patients. World J Gastroenterol 2006;12:4195-4198

23. Mavrogiannou E, Strati A, Stathopoulou A, Tsaroucha EG, Kaklamanis L, Lianidou ES: Real-time rt-PCR quantification of human telomerase reverse transcriptase splice variants in tumor cell lines and non-small cell lung cancer. Clin Chem 2007; 53:53-61

24. Takihana Y, Tsuchida T, Fukasawa M, Araki I, Tanabe N, Takeda M: Real-time quantitative analysis for human telomerase reverse transcriptase mRNA and human telomerase RNA component mRNA expressions as markers for clinicopathologic parameters in urinary bladder cancer. Int J Urol 2006;13:401-408

25. Balch CM, Buzaid AC, Atkins MB et al: A new American Joint Committee on Cancer staging system for cutaneous melanoma. Cancer 2000, 88:1484-1491
26. Balch CM, Soong SJ, Gershenwald JE et al: Prognostic factors analysis of 17,600 melanoma patients: Validation of the American Joint Committee on Cancer melanoma staging system. J Clin Oncol 2001; 19:3622-3634

27. Balch CM, Buzaid AC, Soong SJ et al: Final version of the American Joint Committee on Cancer staging system for cutaneous melanoma.J Clin Oncol 2001; 19:3635-3648

28. Brochez L, Naeyaert JM: Serological markers for melanoma. Brit J Dermatol 2000; 143: 256-268

29. Koyanagi K, Kuo Ch, Nakagawa T: Multimarker quantitative realtime PCR detection of circulating melanoma cells in peripheral blood: relation to disease stage in melanoma patients. Clin Chem 2005; 51: 981-988

30. Aubin F, Chtourou M, Teyssier JR et al: The detection of tyrosinase mRNA in the peripheral blood of stage I melanoma patients is not of clinical relevance in predicting metastasis risk and survival. Melanoma Res 2000; 10:113-118

31. Pittman K, Burchill S, Smith B et al: Reverse transcriptase-polymerase chain reaction for expression of tyrosinase to identify malignant melanoma cells in peripheral blood. Ann Oncol 1996; 7:297-301.

32. Reinhold U, Ludtke Handjery HC, Schnautz S et al: The analysis of tyrosinase specific mRNA in blood samples of melanoma patients by RT-PCR is not a useful test for metastatic tumor progression. J Invest Dermatol 1997;108:166-169

33. Stevens GL, Scheer WD, Levine EA: Detection of tyrosinase mRNA from the blood of melanoma patients. Cancer Epidemiol Biomarkers Prev 1996; 5:293-296

34. Sarantou T, CHi DDJ, Garrison DA: Melanoma associated antigens as messanger RNA detection markers for melanoma. Cancer Res 1997; 57:1371-1376

35. De Vries TJ, Fourkour A, Punt CJA: Reproducibility of detection of tyrosinase and MART-1 transcripts in the peripheral blood of melanoma patients: a quality control study using real-time quantitative RT-PCR. Br J Cancer 1999; 80: 883-891

36. Pohlreich P, Stříbrná J, Kleibl Z: Detection of neoplastic cells in blood of miniature pigs with hereditary melanoma. Vet Med Czech 2001; 46: 199-204

37. Mocellin S, Hoon D, Ambrosi A, Nitti D, Rossi CR: The prognostic value of circulating tumor cells in patients with melanoma: a systematic review and meta-analysis. Clin Cancer Res 2006; 12: $4605-4613$ 